\title{
Seroprevalence of toxoplasmosis in pregnant women of the Marrakech-Safi region, Morocco
}

Laila Hoummadi ${ }^{1}$, Salma Berrouch ${ }^{1}$, Yassine Amraouza ${ }^{1}$, Abdelaziz Adel ${ }^{2}$, Mostafa Mriouch $^{3}$, Nabila Soraa $^{4}$, Younes El Jahiri ${ }^{5}$, Laila Zoughari ${ }^{6}$, Abdelkrim Benbouzid ${ }^{7}$, El Mostafa Miss ${ }^{8}$, Redouan Moutaj ${ }^{9}$, Jamaleddine Hafid ${ }^{1}$

1. Laboratory of Foods, Environment and Health. Faculty of Sciences and Techniques-Gueliz, Cadi Ayyad University, Marrakech.

2. Laboratory of medical analysis Achifa, El Kelaâ des Sraghna.

3. Laboratory of medical analysis Mogador, Essaouira.

4. Laboratory of Bacteriology - Virology - Hospital Arrazi - CHU Mohammed VI, Marrakech.

5. Biocentre Laboratory of analysis of medical biology, Marrakech.

6. Laboratory Dar Albir of medical analysis, Marrakech.

7. Laboratory of medical and scientific analysis, Safi.

8. Medical analysis laboratory, provincial hospital Mohammed V, Safi.

9. Service of Parasitology-Mycology, Military Hospital Avicenne, Marrakech.

\begin{abstract}
:
Background: Toxoplasmosis is a parasitic infection caused by an intracellular protozoan named Toxoplasma gondii. Its prevalence had been investigated in several studies throughout the world showing that it varied from one country to another. In contrast, few studies had been carried out on this infection across the kingdom of Morocco, hence the objective of this work, which is the determination of Toxoplasma gondii seroprevalence in the region of Marrakech-Safi.

Methods: The serological results of a cohort of 5692 patients were reviewed retrospectively. Those patients had been into different public and private medical laboratories in the region of Marrakech-Safi for a toxoplasmosis serology, requested between the $1^{\text {st }}$ January, 2014 and $31^{\text {st }}$ December, 2016. According to each laboratory, the techniques adopted for this serology were ELISA (ELFA, MEIA, EIA) and CMIA.
\end{abstract}

Results: The results showed that for pregnant women, the overall seroprevalence in the study region were $28.88 \%$.

Conclusion: The variation of Toxoplasma gondii seroprevalence is related not only to climatic factors but also to lifestyle, eating habits, socio-economic status and hygiene conditions. In this study, we noticed that in Morocco, as in other countries, pregnant women encounter several difficulties when serologic screening for toxoplasmosis.

Keywords: Seroprevalence, Toxoplasmosis, pregnant women, Marrakech-Safi region.

DOI: https://dx.doi.org/10.4314/ahs.v20i1.10

Cite as: Hoummadi L, Berrouch S, Amraouza Y, Adel A, Mriouch M, Soraa N, et al. Seroprevalence of toxoplasmosis in pregnant women of the Marrakech-Safi region, Morocco. Afri Health Sci. 2020;20(1):59-63. https:// dx.doi.org/10.4314/abs.v20i1.10

\section{Introduction}

Toxoplasmosis is one of the more common parasitic zoonoses world-wide, caused by the protozoan named Toxoplasma gondii. ${ }^{1-2-3}$ This parasite is capable to infects virtually

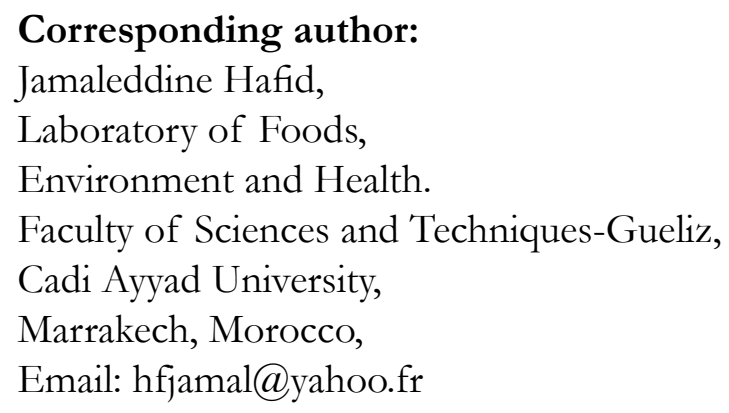

all warm-blooded animals. Felids such as domestic cats are the only known definitive hosts in which the parasite may undergo sexual reproduction. ${ }^{2-3-4-5}$ The seropositivity infection is highly variable depending on the country. It depends on the living conditions, culinary habits, cultural and economic factors, climatic factors and hygienic conditions $^{1-3-6}$.

Humans are infected by ingestion of cysts in meat products or by ingestion of soil, water or food contained sporulated oocysts from faces of felines. However, the relative share of the different modes of contamination remains poorly known ${ }^{7-11}$. Under these usual circumstances, it is necessary to add transmission by transplacental route,

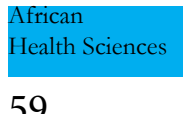

(C) 2020 Hoummadi L et al. Licensee African Health Sciences. This is an Open Access article distributed under the terms of the Creative commons Attribution License (https://creativecommons.org/licenses/BY/4.0), which permits unrestricted use, distribution, and reproduction in any medium, provided the original work is properly cited. 
organ transplantation, transfusion and rarely laboratory containation. In Morocco, a few works have been devoted to T. gondii, in general and to human and animal toxoplasmosis in particular, despite the consequences that this infection may cause.

Indeed, the few studies carried out since the 1970s to evaluate the seroprevalence of toxoplasmosis in humans have shown that it varied from one city to another, ranging from 33.3\% among women of child bearing age in Marrakech city to $50.6 \%$ among pregnant women in $\mathrm{Ra}$ bat city ${ }^{12,13}$, however the national prevalence of toxoplasmosis remained unknown. Moreover, in order to know the rate of $T$. gondii carriage by animals intended for human consumption and consequently their role in the contamination by this parasite, an epidemiological study, have been carried out in 2004 by Belbacha and collaborators ${ }^{14}$, in Marrakech on sheep and revealed a rate of $30 \%$, which is very close to that found by Sawadogo and collaborators in $2005^{15}$. Otherwise, a lower prevalence of $9.87 \%$ was found in cattle in $2008^{16}$, in the same region.
The objective of our study is to retrospectively determine the seroprevalence of toxoplasmosis among pregnant women in four cities in Marrakech-Safi region, and to explain, as far as possible, its relation to climatic and socio-economic factors. This will make it possible to assess the quantitative risk related to this parasitosis.

\section{Material and methods \\ Population studied}

This study was performed in Marrakech-Safi region.

It is located in the center of Morocco and made up into the following citys: Al Haouz, Chichaoua, El Kelâa des Sraghna, Essaouira, Marrakech, Rehamna, Safi and Youssoufia.

To determine the effect of climate on seroprevalence, the study was carried out in four cities. Two coastal cities (Essaouira and Safi) and two indoor cities (Marrakech and El kalaa des Sraghna) (figure 1).

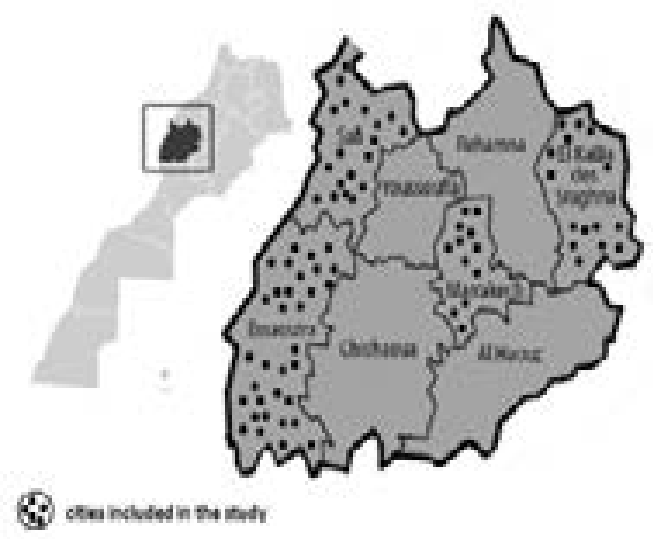

Figure 1: Map of sampling localities

This retrospective study involved a cohort of 5692 patients. These patients were sent to eight public and private medical laboratories in the region of Marrakech-Safi, for serological of toxoplasmosis between 1 January 2014 and 31 December 2016. In more than 98\% of cases, it was systematic pregnancy-related surveillance. All data were collected in public and private medical analysis laboratories while respecting ethics.

\section{Serological tests}

According to each laboratory, the techniques adopted for this serology are:
The immunoenzymatic techniques ELISA such as ELFA (Vidas ${ }^{\circledR}$ Toxo IgG, Mini Vidas ${ }^{\circledR}$ Toxo $\operatorname{IgG}$ ), MEIA (Axsym ${ }^{\circledR}$ Toxo $\operatorname{Ig} G$ ) and EIA.

- $\quad$ Microparticle immunological Assay CMIA (Architectoxo IgG, Access ${ }^{\circledR}$ 'ToxolgG)

The tests adopted by the laboratories have different thresholds of positivity, for titration of IgG. Our study was based only on the results validated by biologists (positive or negative) without the comparison of the values of the $\mathrm{IgG}$ titers obtained by the laboratories. 


\section{Results}

\section{Socio-demographic data}

The age of patients ranged between 15 and 52 with an av- erage of 27.7 years. The age range for which most pregnant is immune is between 15 and 20 years (Table 1)

Table 1: Serological profile of pregnant women by age group

\begin{tabular}{|c|c|c|c|c|c|c|c|c|}
\hline & \multicolumn{2}{|c|}{ Marrakech } & \multicolumn{2}{|c|}{ Essaouira } & \multicolumn{2}{|r|}{ Safi } & \multicolumn{2}{|c|}{ El Kelaâ des Sraghna } \\
\hline Age range & Number & $\begin{array}{l}\text { Seroprevalence } \\
\%\end{array}$ & Number & $\begin{array}{l}\text { Seroprevalence } \\
\%\end{array}$ & Number & Seroprevalence\% & Number & Seroprevalence\% \\
\hline$<20$ & 60 & 9,56 & 46 & 10,06 & 270 & 18,45 & 62 & 8,25 \\
\hline $20-25$ & 497 & 13,09 & 239 & 16,47 & 569 & 22,56 & 175 & 15,63 \\
\hline $26-30$ & 732 & 21,74 & 308 & 25,65 & 628 & 30,77 & 186 & 23,33 \\
\hline $30-35$ & 159 & 30,50 & 327 & 36,80 & 469 & 38,58 & 144 & 30,48 \\
\hline $36-39$ & 117 & 37 & 86 & 40,15 & 262 & 44,02 & 71 & 37,94 \\
\hline$>40$ & 41 & 42,85 & 12 & 45,29 & 90 & 50,11 & 28 & 42,46 \\
\hline
\end{tabular}

The seroprevalence increased significantly with age: for It also varied with the socio-economic level of mothers, example, from 8,25 to $18,45 \%$ among the under 20 s and with higher seroprevalence among those screened in pub$42,46 \%$ to $52,11 \%$ after 40 years. lic laboratories.

Table 2: T. gondii seroprevalence in pregnant women according to the type of laboratory

\begin{tabular}{|c|c|c|}
\hline \multirow{2}{*}{ City } & \multicolumn{2}{|c|}{ Seroprevalence in \% } \\
\cline { 2 - 3 } & Public Analysis Laboratories & Private analysis laboratories \\
\hline Marrakech & 31,49 & 21,06 \\
\hline Essaouira & -- & 20,92 \\
\hline Safi & 36,42 & 31,27 \\
\hline El & -- & 26,1 \\
Kelaâ des Sraghna & & \\
\hline
\end{tabular}

\section{Serological data}

The results showed that in pregnant women the overall seroprevalence in the Marrakech-Safi region is $28.88 \%$. It is $26.28 \%$ in Marrakech, 28.92\% in Essaouira, 33.84\% in Safi and $26.49 \%$ in El Kelaâ des Sraghna (Table 3).

Table 3: $T$. gondii seroprevalence in pregnant women according to the year.

\begin{tabular}{|c|c|c|c|c|c|}
\hline City Sample & \multicolumn{3}{|c|}{ Seroprevalence\% } & \multirow{2}{*}{ Mean of seropositivity \% } \\
\cline { 3 - 5 } & 2014 & 2015 & 2016 & \\
\hline Marrakech & 1606 & 26,92 & 26,35 & 25,58 & \\
\hline Essaouira & 1018 & 27,69 & 30,21 & 28,86 & 26,28 \\
\hline Safi & 2288 & 36,49 & 33,58 & 31,45 & 28,92 \\
\hline $\begin{array}{c}\text { El } \\
\text { Kelaâ des Sraghna }\end{array}$ & 666 & 26,78 & 26,1 & 26,6 & 26,49 \\
\hline \multicolumn{7}{|c|}{} & & & & \\
\hline Total & $\mathbf{5 5 7 8}$ & $\mathbf{2 9 , 4 7 \%}$ & $\mathbf{2 9 , 0 6 \%}$ & $\mathbf{2 8 , 1 2 \%}$ & $\mathbf{2 8 , 8 8 \%}$ \\
\hline
\end{tabular}




\section{Discussion}

The prevalence that we observed in this work $(28.88 \%)$ is close to that noted by Biava et al. (1983) in the region of Marrakech ${ }^{12}$ which was $33.3 \%$. On the other hand, this prevalence remains lower than that found by El Mansouri et al. 2007 in the region of Rabat $(50.6 \%)^{13}$. The most likely hypothesis to explain the low observed prevalence is related to the climate factor that has a significant effect on oocysts in the environment. The region of Marrakech is semi-arid characterized by very hot summers and harsh winters, which might influence the transmission of parasites, leading to a low probability of their survival. On the other hand, the city of Rabat is characterized by a Mediterranean climate with cool and rainy winters and moderately hot summers, rarely exceeding $30^{\circ} \mathrm{C}$, which would favor the conservation of oocysts in soil and food that are usually consumed raw. Our results confirm those of Lélu et al., ${ }^{6}$ which showed a significant effect of damp and dry conditions on the inactivation of oocysts. Indeed, the proportion of $T$. gondii oocysts surviving after 100 days under dry conditions was estimated to be $7.4 \%$ against $43.7 \%$ in damp conditions.

Unlike the seroprevalence in Essaouira (28.92\%), which is slightly higher than those of the cities of the interior namely Marrakech and El Kelaâ des Sraghna, that of the city of Safi is significantly higher (33, 84\%) (Table 3). This could also be explained by the climate effect on the maintenance and sporulation of $T$. gondii oocysts. In addition, the comparison of seroprevalence within cities during the three years of study shows that it does not fluctuate significantly from year to year.

On an international scale, our result of $28,88 \%$ is close to that determined in some countries as Libya (Tripoli) $18,14 \%{ }^{17}$ and Mali (Kolle) $27 \%{ }^{18}$ On the other hand high prevalences have been identified in other countries such as Madagascar (Antananarivo) 83,5\% ${ }^{19}$, Congo (Kinshasa) $80,3 \%{ }^{20}$, Cameroun (Douala) $77 \% 0^{21}$. These differences can be explained by the climatic factors that influence transmission of the parasite. In Africa, there is a gradient of seroprevalence from $10 \%$ in semi-arid areas to nearly $80 \%$ in the wet tropics ${ }^{22}$. The variation of prevalence between these studies is related not only to climatic factors but also very often to lifestyle, eating habits, socio-economic status and hygiene conditions.

According to this study the main factors associated with prevalence were age and region. In Morocco the prev- alence of toxoplasmosis in pregnant women increases with age (Table 1), this relationship has already been observed in several studies ${ }^{13-23-24-25}$.

The seropositivity rates recorded in public laboratories were higher than those recorded in private, The highest rate was observed in Marrakech as showed in table 2. This could be explained by a difference in the socio-economic level of patients (economic level, level of education). In fact, most patients who had access to private laboratories are informed and advised by their gynecologist about anti-Toxoplasma prevention, and are able to bear the cost of analysis. On the other hand, the majority of those who are screened in public laboratories are beneficiaries of the Medical Assistance Plan (RAMED), and have never heard of toxoplasmosis

We also found that there is a lack of monitoring during pregnancy, knowing that only $11 \%$ of pregnant women in our study were followed during their pregnancies, of which $76.4 \%$ received only a single control seropositivity, which is very low compared to the number of monthly serological tests for toxoplasmosis recommended in pregnant women.

\section{Conclusion}

The overall seroprevalence of toxoplasmosis in pregnant women in our study is $28.88 \%$. These data show that $71.22 \%$ of pregnant women are likely to become infected during pregnancy because of their lack of antitoxoplasmic immunity with a risk of congenital toxoplasmosis for the fetus.

The variation in prevalence is related not only to climatic factors, but also very often to lifestyle, dietary habits, socio-economic status and hygiene conditions. It would be interesting to extend this survey to the others regions of Morocco.

\section{Conflict of interest}

None delcared.

\section{References}

1. AFSSA. Toxoplasmose: état des connaissances et évaluation du risque lié à l'alimentation. Rapport du groupe de travail «T. gondï». Paris: Agence Française de Sécurité Sanitaire des Aliments 2005; 318p.

2. Dubey JP. Toxoplasmosis of animals and humans. CRC Press, Boca. Rotan 2010; 336 p 
3. Tenter A M, Heckeroth A R., Weiss L M. Toxoplasma gondii from animals to humans. Inter J Parasitol. 2000; 30:1217-1258 .

4. Afonso E, Thulliez P, Gilot-Fromont E. Local meteorological conditions, dynamics of seroconversion to Toxoplasma gondii in cats (Feliscatus) and oocyst burden in a rural environment. Epidemiol Infect. 2010; 138:11051113.

5. Pappas G, Roussos N, Falagas ME. Global status of Toxoplasma gondii seroprevalence and implications for pregnancy and congenital toxoplasmosis. Inter J Parasitol. 2009; 39:1385-1394.

6. Lélu M, Villena V, Dardé ML, et al. Quantitative Estimation of the Viability of Toxoplasma gondii Oocysts in Soil. Appl Environ Microbiol. 2012; 78: 5127-5132.

7. Cenci-Goga B.T, Rossitto P.V, Sechi P, et al. Toxoplasma in animals, food, and humans : an old parasite of new concern. Foodborne Pathog Dis. 2011; 8 : 751762.

8. Dawson D. Foodborne protozoan parasites. Inter J Food Microbiol. 2005; 103:207-227.

9. Dubey JP. Toxoplasmosis - a waterborne zoonosis. Vet Parasitol. 2004;126:57-72.

10. Montoya J G, Liesenfeld O. Toxoplasmosis. The Lancet. 2004; 363: 1965-1976.

11. Villena I, Durand B, Aubert D, et al. New strategy for the survey of Toxoplasma gondii in meat for human consumption. Vet Parasitol. 2012; 183: 203-208.

12. Biava M.F, Jana M., EL Mansouri A, et al. Etude séro- épidémiologique de la toxoplasmose à Marrakech. Méd Mal Infect. 1983; 13: 503 - 506.

13. El Mansouri B, Rhajaoui M, Sebti F, et al. Séroprévalence de la toxoplasmose chez les femmes enceintes à Rabat. Bull Soc Pathol Exot. 2007; 100: 113- 116.

14. Belbacha I, Hafid J, TranManh R et al. Toxoplasma gondii: Taux de portage chez les ovins de la région de Marrakech (Mnabha). Schweiz. Arch Tierbeilked. 2004; 146:561564.
15. Sawadogo P, Hafid J, Bellete B, et al. Seroprevalence of $T$. gondii in sheep from Marrakech, Morocco, Vet Parasitol. 2005; 130: 89-92.

16. Sawadogo P, Bellete B, Flori P, et al. Detection of Anti-Toxoplasma gondii Antibodies in Cattle in Marrakech, Morocco. Parasitol Unit J. 2008; 2: 149 - 151.

17. Abo Setta A M, yamani R H. Prevalence of toxoplasmosis in non-pregmentwonen in tripoli, libya. Egypt J Hosp Med. 2008; 31:198-202.

18. Ouologuem DT, Djimde A, Diallo N, et al. Toxoplasma gondii seroprevalence in Mali. J Parasitol. 2013 ; 99 :371-374.

19. Lelong B, Rahelimino B, Candolfi E, et al. Prévalence de la toxoplasmose dans une population de femmes enceintes à Tananarive (Madagascar). Bull Soc Pathol Exot. 1995; 88: 46-49.

20. Yobi D, Piarroux R, L'Ollivier C, et al. Toxoplasmosis among pregnant women: High seroprevalence and risk factors in Kinshasa, Democratic Republic of Congo. Asian Pac J Trop Biomed. 2014;4: 69-74.

21. Njunda A, Assob J, Nsagha D, et al. Seroprevalence of Toxoplasma gondii infection among pregnant women in Cameroon. J Pub Health Afr. 2011; 2: 98-101.

22. K Hammond-Aryee, M Esser, PD Van Helden. Toxoplasma gondii seroprevalence studies on humans and animals in Africa. S Afr Fam Pract. 2014; 56: 119-124.

23. Allain JP, Palmer CR , Pearson G . Epidemiological study of latent and recent infection by Toxoplasma gondii in pregnant women from a regional population in the UK. J Infect. 1998; 36: 189-196.

24. Bobic B, Jevremovic I, Marinkovic J, Sibalic D, Djurkovic-Djakovic O. Risk factors of toxoplasma infection in a reproductive age female population in the area of Belgrade, Yugoslavia. Eur J Epidemiol. 1998; 14: 605610.

25. Joshi YR, Vyas S, Joshi KR . Seroprevalence of toxoplasmosis in Jodhpur, India. J Commun Dis. 1998; 30:32-37. 